\title{
Language and woman's place
}

\author{
ROBIN LAKOFF \\ Department of Linguistics, University of California, Berkeley
}

\section{ABSTRACT}

Our use of language embodies attitudes as well as referential meanings. 'Woman's language' has as foundation the attitude that women are marginal to the serious concerns of life, which are pre-empted by men. The marginality and powerlessness of women is reflected in both the ways women are expected to speak, and the ways in which women are spoken of. In appropriate women's speech, strong expression of feeling is avoided, expression of uncertainty is favored, and means of expression in regard to subject-matter deemed 'trivial' to the 'real' world are elaborated. Speech about women implies an object, whose sexual nature requires euphemism, and whose social roles are derivative and dependent in relation to men. The personal identity of women thus is linguistically submerged; the language works against treatment of women, as serious persons with individual views.

These aspects of English are explored with regard to lexicon (color terms, particles, evaluative adjectives), and syntax (tag-questions, and related aspects of intonation in answers to requests, and of requests and orders), as concerns speech by women. Speech about women is analyzed with regard to lady : woman, master : mistress, widow : widower, and $M r$ : Mrs., Miss, with notice of differential use of role terms not explicitly marked for sex (e.g. professional) as well.

Some suggestions and conclusions are offered for those working in the women's liberation movement and other kinds of social reform; second language teaching; and theoretical linguistics. Relevant generalizations in linguistics require study of social mores as well as of purely linguistic data.

\section{INTRODUCTION}

Languages uses us as much as we use language. As much as our choice of forms of expression is guided by the thoughts we want to express, to the same extent the way we feel about the things in the real world governs the way we express ourselves about these things. Two words can be synonymous in their denotative sense, but one will be used in case a speaker feels favorably toward the object the word denotes, the other if he is unfavorably disposed. Similar situations are legion, involving unexpectedness, interest, and other emotional reactions on the part of the speaker to what he is talking about. Thus, while two speakers may 
be talking about the same thing or real-world situation their descriptions may end up sounding utterly unrelated. The following well-known paradigm will be illustrative.

(I) (a) I am strong-minded.

(b) You are obstinate.

(c) $\mathrm{He}$ is pigheaded.

If it is indeed true that our feelings about the world color our expression of our thoughts, then we can use our linguistic behavior as a diagnostic of our hidden feelings about things. For often - as anyone with even a nodding acquaintance with modern psychoanalytic writing knows too well - we can interpret our overt actions, or our perceptions, in accordance with our desires, distorting them as we see fit. But the linguistic data are there, in black and white, or on tape, unambiguous and unavoidable. Hence, while in the ideal world other kinds of evidence for sociological phenomena would be desirable along with, or in addition to, linguistic evidence, sometimes at least the latter is all we can get with certainty. This is especially likely in emotionally-charged areas like that of sexism and other forms of discriminatory behavior. This paper, then, is an attempt to provide diagnostic evidence from language use for one type of inequity that has been claimed to exist in our society: that between the roles of men and women. I will attempt to discover what language use can tell us about the nature and extent of any inequity; and finally to ask whether anything can be done, from the linguistic end of the problem: does one correct a social inequity by changing linguistic disparities? We will find, I think, that women experience linguistic discrimination in two ways: in the way they are taught to use language, and in the way general language use treats them. Both tend, as we shall see, to relegate women to certain subservient functions: that of sex-object, or servant; and that therefore certain lexical items mean one thing applied to man, another to women, a difference that cannot be predicted except with reference to the different roles the sexes play in society.

The data on which I am basing my claims have been gathered mainly by introspection: $I$ have examined my own speech and that of my acquaintances, and have used my own intuitions in analyzing it. I have also made use of the media: in some ways, the speech heard, e.g., in commercials or situation comedies on television mirrors the speech of the television-watching community: if it did not (not necessarily as an exact replica, but perhaps as a reflection of how the audience sees itself or wishes it were) it would not succeed. The sociologist, anthropologist or ethnomethodologist familar with what seem to him more error-proof data-gathering techniques, such as the recording of random conversation, may object that these introspective methods may produce dubious results. But first, it should be noted that any procedure is at some point introspective: the gatherer must analyze his data, after all. Then, one necessarily selects 


\section{LANGUAGE AND WOMAN'S PLACE}

a subgroup of the population to work with: is the educated, white, middle-class group that the writer of the paper identifies with less worthy of study than any other? And finally, there is the purely pragmatic issue: random conversation must go on for quite some time, and the recorder must be exceedingly lucky anyway, in order to produce evidence of any particular hypothesis, e.g. that there is sexism in language, that there is not sexism in language. If we are to have a good sample of data to analyze, this will have to be elicited artificially from someone; I submit I am as good an artificial source of data as anyone.

These defenses are not meant to suggest that either the methodology or the results are final, or perfect. This paper is meant to suggest one possible approach to the problem, one set of facts. I do feel that the majority of the claims I make will hold for the majority of speakers of English; that, in fact, much may, mutatis mutandis, be universal. But granting that this paper does in itself represent the speech of only a small subpart of the community, it is still of use in indicating directions for further research in this area: in providing a basis for comparison, a taking-off point for further studies, a means of discovering what is universal in the data and what is not, and why. That is to say, I present what follows less as the final word on the subject of sexism in language - anything but that ! - than as a goad to further research.

If a little girl 'talks rough' like a boy, she will normally be ostracized, scolded, or made fun of. In this way society, in the form of a child's parents and friends, keeps her in line, in her place. This socializing process is, in most of its aspects, harmless and often necessary, but in this particular instance - the teaching of special linguistic uses to little girls - it raises serious problems, though the teachers may well be unaware of this. If the little girl learns her lesson well, she is not rewarded with unquestioned acceptance on the part of society; rather, the acquisition of this special style of speech will later be an excuse others use to keep her in a demeaning position, to refuse to take her seriously as a human being. Because of the way she speaks, the little girl - now grown to womanhood - will be accused of being unable to speak precisely or to express herself forcefully. ${ }^{1}$

[r] I am sure that this paragraph contains an oversimplified description of the languagelearning process in U.S. society. Rather than saying that little boys and little girls, from the very start, learn two different ways of speaking, I think, from observation and reports by others, that the process is more complicated. Since the mother and other women are the dominant influences in the lives of most children under the age of five probably both boys and girls first learn 'women's language', as their first language. (I am told that in Japanese, children of both sexes use the particles proper for women until the age of five or so; then the little boy starts to be ridiculed if he uses them, and so soon learns to desist.) As they grow older, boys especially go through a stage of rough talk, as described by Spock and others; this is probably discouraged in little girls more strongly than in little boys, in whom parents may often find it more amusing than shocking. By the time children are ten or so, and split up into same-sex peer groups, the two languages are already present, according to my recollections and observations. But it seems that what has happened is that the boys have unlearned their original form of expression, and adopted new forms of expression, while the girls 
So a girl is damned if she does, damned if she doesn't. If she refuses to talk like a lady, she is ridiculed and subjected to criticism as unfeminine; if she does learn, she is ridiculed as unable to think clearly, unable to take part in a serious discussion: in some sense, as less than fully human. These two choices which a woman has - to be less than a woman or less than a person-are highly painful.2

It will be found that the overall effect of 'women's language' - meaning both language restricted in use to women and language descriptive of women alone is this: it submerges a woman's personal identity, by denying her the means of expressing herself strongly, on the one hand, and encouraging expressions that suggest triviality in subject-matter and uncertainty about it; and, when a woman is being discussed, by treating her as an object - sexual or otherwise - but never a serious person with individual views. Of course, other forms of behavior in this society have the same purpose; but the phenomena seem especially clear linguistically.

The ultimate effect of these discrepancies is that women are systematically denied access to power, on the grounds that they are not capable of holding it as demonstrated by their linguistic behavior along with other aspects of their behavior; and the irony here is that women are made to feel that they deserve such treatment, because of inadequacies in their own intelligence and/or education. But in fact it is precisely because women have learned their lessons so well that they later suffer such discrimination. (This situation is of course true to some extent for all disadvantaged groups: white males of Anglo-Saxon descent set the standards and seem to expect other groups to be respectful of them but not to adopt them - they are to 'keep in their place'.)

retain their old ways of speech. (One wonders whether this is related in any way to the often-noticed fact that little boys innovate, in their play, much more than little girls.) The ultimate result is the same, of course, whatever the interpretation.

[2] An objection may be raised there that I am overstating the case against women's language, since most women who get as far as college learn to switch from women's to neutral language under appropriate situations (in class, talking to professors, at job interviews, etc.). But I think this objection overlooks a number of problems. First, if a girl must learn two dialects, she becomes in effect a bilingual. Like many bilinguals, she may never really be master of either language, though her command of both is adequate enough for most purposes, she may never feel really comfortable using either, and never be certain that she is using the right one in the right place to the right person. Shifting from one language to another requires special awareness to the nuances of social situations, special alertness to possible disapproval. It may be that the extra energy that must be (subconsciously or otherwise) expended in this game is energy sapped from more creative work, and hinders women from expressing themselves as well as they might otherwise, or as fully or freely as they might otherwise. Thus, if a girl knows that a professor will be receptive to comments that sound scholarly, objective, unemotional, she will of course be tempted to use neutral language in class or in conference. But if she knows that, as a man, he will respond more approvingly to her at other levels if she uses women's language, and sounds frilly and feminine, won't she be confused as well as sorely tempted in two directions at once? It is often noticed that women participate less in class discussion than men - perhaps this linguistic indecisiveness is one reason why. Incidentally, I don't find this true in my classes. 


\section{LANGUAGE AND WOMAN'S PLACE}

I should like now to talk at length about some specific examples of linguistic phenomena I have described in general terms above. I want to talk first about the ways in which women's speech differs from men's speech; and then, to discuss a number of cases in which it seems clear that women are discriminated against (usually unconsciously) by the language everyone uses. I think it will become evident from this discussion that both types of phenomena reflect a deep bias on the part of our culture (and, indeed, of every culture I have ever heard of) against women being accorded full status as rational creatures and individuals in their own right; and finally, I would like to talk briefly about what might be done, and perhaps what should not be done, to remedy things.

\section{TALKING LIKE A LADY}

'Women's language' shows up in all levels of the grammar of English. We find differences in the choice and frequency of lexical items; in the situations in which certain syntactic rules are performed; in intonational and other supersegmental patterns. As an example of lexical differences, imagine a man and a woman both looking at the same wall, painted a pinkish shade of purple. The woman may say (2):

(2) The wall is mauve,

with no one consequently forming any special impression of her as a result of the words alone; but if the man should say (2), one might well conclude he was either imitating a woman sarcastically, or a homosexual, or an interior decorator. Women, then, make far more precise discriminations in naming colors than do men; words like beige, ecru, aquamarine, lavender, and so on, are unremarkable in a women's active vocabulary, but absent from that of most men. I have seen a man helpless with suppressed laughter at a discussion between two other people as to whether a book-jacket was to be described as 'lavender' or 'mauve'. Men find such discussion amusing because they consider such a question trivial, irrelevant to the real world.

We might ask why fine discrimination of color is relevant for women, but not for men. A clue is contained in the way many men in our society view other 'unworldly' topics, e.g. high culture and the Church, as outside the world of men's work, relegated to women and men whose masculinity is not unquestionable. Men tend to relegate to women things that are not of concern to them, or do not involve their egos. Among these are problems of fine color discrimination. We might rephrase this point by saying that since women are not expected to make decisions on important matters, like what kind of job to hold, they are relegated the non-crucial decisions as a sop. Deciding whether to name a color 'lavender' or 'mauve' is one such sop.

If it is agreed that this lexical disparity reflects a social inequity in the position of women, one may ask how to remedy it. Obviously, no one could seriously 


\section{LANGUAGE IN SOCIETY}

recommend legislating against the use of the terms 'mauve' and 'lavender' by women, or forcing men to learn to use them. All we can do is give women the opportunity to participate in the real decisions of life.

Aside from specific lexical items like color-names, we find differences between the speech of women and that of men in the use of particles that grammarians often describe as 'meaningless'. There may be no referent for them, but they are far from meaningless: they define the social context of an utterance, indicate the relationship the speaker feels between himself and his addressee, between himself and what he is talking about.

As an experiment, one might present native speakers of standard American English with pairs of sentences, identical syntactically, and in terms of referential lexical items, and differing merely in the choice of 'meaningless' particle, and ask them which was spoken by a man, which a woman. Consider:

(3) (a) Oh dear, you've put the peanut butter in the refrigerator again.

(b) Shit, you've put the peanut butter in the refrigerator again.

It is safe to predict that people would classify the first sentence as part of 'women's language', the second as 'men's language'. It is true that many selfrespecting women are becoming able to use sentences like $(3)(b)$ publicly without flinching, but this is a relatively recent development, and while perhaps the majority of Middle America might condone the use of $(b)$ for men, they would still disapprove of its use by women. (It is of interest, by the way, to note that men's language is increasingly being used by women, but women's language is not being adopted by men, apart from those who reject the American masculine image (e.g. homosexuals). This is analogous to the fact that men's jobs are being sought by women, but few men are rushing to become housewives or secretaries. The language of the favored group, the group that holds the power, along with its non-linguistic behavior, is generally adopted by the other group, not viceversa. In any event, it is a truism to state that the 'stronger' expletives are reserved for men, and the 'weaker' ones for women.)

Now we may ask what we mean by 'stronger' and 'weaker' expletives. (If these particles were indeed meaningless, none would be stronger than any other.) The difference between using 'shit' (or 'damn', or one of many others) as opposed to 'oh dear', or 'goodness', or 'oh fudge' lies in how forcefully one says how one feels - perhaps, one might say, choice of particle is a function of how strongly one allows oneself to feel about something, so that the strength of an emotion conveyed in a sentence corresponds to the strength of the particle. Hence in a really serious situation, the use of 'trivializing' (that is, 'women's') particles constitutes a joke, or at any rate, is highly inappropriate.

(4) (a) *Oh fudge, my hair is on fire.

(b) *Dear me, did he kidnap the baby?

As children, women are encouraged to be 'little ladies'. Little ladies don't 
scream as vociferously as little boys, are chastised more severely for throwing tantrums or showing temper: 'high spirits' are expected and therefore tolerated in little boys; docility and resignation are the corresponding traits expected of little girls. Now, we tend to excuse a show of temper by a man where we would not excuse an identical tirade from a woman: women are allowed to fuss and complain, but only a man can bellow in rage. It is sometimes claimed that there is a biological basis for this behavior difference, though I don't believe conclusive evidence exists that the early differences in behavior that have been observed are not the results of very different treatment of babies of the two sexes from the beginning; but surely the use of different particles by men and women is a learned trait, merely mirroring nonlinguistic differences again, and again pointing out an inequity that exists between the treatment of men, and society's expectations of them, and the treatment of women. Allowing men stronger means of expression than are open to women further reinforces men's position of strength in the real world: for surely we listen with more attention the more strongly and forcefully someone expresses opinions, and a speaker unable - for whatever reason - to be forceful in stating his views, is much less likely to be taken seriously. Ability to use strong particles like 'shit' and 'hell' is, of course, only incidental to the inequity that exists rather than its cause. But once again, apparently accidental linguistic usage suggests that women are denied equality partially for linguistic reasons, and that an examination of language points up precisely an area in which inequity exists. Further, if someone is allowed to show emotions, and consequently does, others may well be able to view him as a real individual in his own right, as they could not if he never showed emotion. Here again, then, the behavior a woman learns as 'correct' prevents her from being taken seriously as an individual, and further is considered 'correct' and necessary for a woman precisely because society does not consider her seriously as an individual.

Similar sorts of disparities exist elsewhere in the vocabulary. There is, for instance, a group of adjectives which have, besides their specific and literal meanings, another use, that of indicating the speaker's approbation or admiration for something. Some of these adjectives are neutral as to sex of speaker: either men or women may use them. But another set seems, in its figurative use, to be largely confined to women's speech. Representative lists of both types are below:

$\begin{array}{ll}\text { neutral } & \text { women only } \\ \text { great } & \text { adorable } \\ \text { terrific } & \text { charming } \\ \text { cool } & \text { sweet } \\ \text { neat } & \text { lovely } \\ & \text { divine }\end{array}$

As with the color-words and swear-words already discussed, for a man to stray 


\section{LANGUAGE IN SOCIETY}

into the 'women's' column is apt to be damaging to his reputation, though here a woman may freely use the neutral words. But it should not be inferred from this that a woman's use of the 'women's' words is without its risks. Where a woman has a choice between the neutral words and the women's words, as a man has not, she may be suggesting very different things about her own personality and her view of the subject matter by her choice of words of the first set or words of the second.

(5) (a) What a terrific idea!

(b) What a divine idea!

It seems to me that (a) might be used under any appropriate conditions by a female speaker. But $(b)$ is more restricted. Probably it is used appropriately (even by the sort of speaker for whom it was normal) only in case the speaker feels the idea referred to to be essentially frivolous, trivial, or unimportant to the world at large - only an amusement for the speaker herself. Consider, then, a woman advertising executive at an advertising conference. However feminine an advertising executive she is, she is much more likely to express her approval with (5) (a), than with (b), which might cause raised eyebrows, and the reaction, 'That's what we get for putting a woman in charge of this company.'

On the other hand, suppose a friend suggests to the same woman that she should dye her French poodles to match her cigarette lighter. In this case, the suggestion really concerns only her, and the impression she will make on people. In this case, she may use $(b)$, from the 'woman's language'. So the choice is not really free: words restricted to 'women's language' suggest that concepts to which they are applied are not relevant to the real world of (male) influence and power.

One may ask whether there really are no analogous terms that are available to men - terms that denote approval of the trivial, the personal; that express approbation in terms of one's own personal emotional reaction, rather than by gauging the likely general reaction. There does in fact seem to be one such word: it is the recent hippie invention 'groovy', which seems to have most of the connotations that separate 'lovely' and 'divine' from 'great' and 'terrific' excepting only that it does not mark the speaker as feminine or effeminate.

(6) (a) What a terrific steel mill!

(b) *What a lovely steel mill! (male speaking)

(c) What a groovy steel mill!

I think it is significant that this word was introduced by the hippies, and, when used seriously rather than sarcastically, used principally by people who have accepted the hippies' values. Principal among these is the denial of the Protestant work ethic: to a hippie, something can be worth thinking about even if it isn't influential in the power structure, or money-making. Hippies are separated from the activities of the real world just as women are - though in the former case it is 


\section{LANGUAGE AND WOMAN'S PLACE}

due to a decision on their parts, while this is not uncontroversially true in the case of women. For both these groups, it is possible to express approval of things in a personal way - though one does so at the risk of losing one's credibility with members of the power structure. It is also true, according to some speakers, that upper-class British men may use the words listed in the 'women's' column, as well as the specific color words and others we have categorized as specifically feminine, without raising doubts as to their masculinity among other speakers of the same dialect. (This is not true for lower-class Britons, however.) The reason may be that commitment to the work ethic need not necessarily be displayed: one may be or appear to be a gentleman of leisure, interested in various pursuits, but not involved in mundane (business or political) affairs, in such a culture, without incurring disgrace. This is rather analogous to the position of a woman in American middleclass society, so we should not be surprised if these special lexical items are usable by both groups. This fact points indeed to a more general conclusion. These words aren't, basically, 'feminine'; rather, they signal 'uninvolved', or 'out of power'. Any group in a society to which these labels are applicable may presumably use these words; they are often considered 'feminine', 'unmasculine', because women are the 'uninvolved', 'out of power' group par excellence.

Another group that has, at least partially, taken itself out of the search for power and money, is that of academic men. They are frequently viewed by other groups as analogous in some ways to women - they don't really work, they are supported in their frivolous pursuits by others, what they do doesn't really count in the real world, and so on. The suburban home finds its counterpart in the ivory tower: one is supposedly shielded from harsh realities in both. Therefore it is not too surprising that many academic men and ministers (especially those who emulate British norms) may violate many of these sacrosanct -rules I have just laid down: they often use 'women's language'. Among themselves, this does not occasion ridicule. But to a truck driver, a professor saying, 'What a lovely hat!' is undoubtedly laughable, all the more so as it reinforces his stereotype of professors as effete snobs.

When we leave the lexicon and venture into syntax, we find that syntactically too women's speech is peculiar. To my knowledge, there is no syntactic rule in English that only women may use. But there is at least one rule that a woman will use in more conversational situations than a man. (This fact indicates, of course, that the applicability of syntactic rules is governed partly by social context - the positions in society of the speaker and addressee, with respect to each other, and the impression one seeks to make on the other.) This is the rule of tag-question formation. ${ }^{3}$

[3] Within the lexicon itself, there seems to be a parallel phenomenon to tag-question usage, which I refrain from discussing in the body of the text because the facts are controversial and I do not understand them fully. The intensive so, used where purists 
A tag, in its usage as well as its syntactic shape (in English) is midway between an outright statement and a yes-no question: it is less assertive than the former, but more confident than the latter. Therefore it is usable under certain contextual situations: not those in which a statement would be appropriate, nor those in which a yes-no question is generally used, but in situations intermediate between these.

One makes a statement when one has confidence in his knowledge and is pretty certain that his statement will be believed; one asks a question when one lacks knowledge on some point, and has reason to believe that this gap can and will be remedied by an answer by the addressee. A tag question, being intermediate between these, is used when the speaker is stating a claim, but lacks full confidence in the truth of that claim. So if I say

(7) Is John here?

I will probably not be surprised if my respondent answers 'no'; but if I say

(8) John is here, isn't he?

instead, chances are I am already biased in favor of a positive answer, wanting only confirmation by the addressee. I still want a response from him, as I do with a yes-no question; but I have enough knowledge (or think I have) to predict that response, much as with a declarative statement. A tag question, then, might be thought of as a declarative statement without the assumption that the statement is to be believed by the addressee: one has an out, as with a question. A tag gives the addressee leeway, not forcing him to go along with the views of the speaker.

There are situations in which a tag is legitimate, in fact the only legitimate sentence-form. So for example, if I have seen something only indistinctly, and have reason to belleve my addressee had a better view, I can say:

would insist upon an absolute superlative, heavily stressed, seems more characteristic of women's language than of men's, though it is found in the latter, particularly in the speech of male academics. Consider, for instance, the following sentences:

(a) I feel so unhappy!

(b) That movie made me so sick!

Men seem to have the least difficulty using this construction when the sentence is unemotional, or nonsubjective - without reference to the speaker himself:

(c) That sunset is so beautiful!

(d) Fred is so dumb!

Substituting an equative like so for absolute superlatives (like very, really, utterly) seems to be a way of backing out of committing oneself strongly to an opinion, rather like tag questions (cf. discussion below, in the text). One might hedge in this way with perfect right in making esthetic judgments (as in (c)) or intellectual judgments (as in $(d)$ ). But it is somewhat odd to hedge in describing one's own mental or emotional state: who, after all, is qualified to contradict one on this? To hedge in this situation is to seek to avoid making any strong statement: a characteristic, as we have' noted already and shall note further, of women's speech. 
(9) I had my glasses off. He was out at third, wasn't he?

Sometimes we find a tag-question used in cases where the speaker knows as well as the addressee what the answer must be, and doesn't need confirmation. One such situation is when the speaker is making 'small talk', trying to elicit conversation from the addressee:

(I0) Sure is hot here, isn't it?

In discussing personal feelings or opinions, only the speaker normally has any way of knowing the correct answer. Strictly speaking, questioning one's own opinions is futile. Sentences like (II) are usually ridiculous.

(II) *I have a headache, don't I?

But similar cases do, apparently, exist, where it is the speaker's opinions, rather than perceptions, for which corroboration is sought, as in (12):

(12) The war in Vietnam is terrible, isn't it?

While there are of course other possible interpretations of a sentence like this, one possibility is that the speaker has a particular answer in mind - 'yes' or 'no' but is reluctant to state it baldly. It is my impression, though I do not have precise statistical evidence, that this sort of tag question is much more apt to be used by women than by men. If this is indeed true, why is it true?

These sentence-types provide a means whereby a speaker can avoid committing himself, and thereby avoid coming into conflict with the addressee. The problem is that, by so doing, a speaker may also give the impression of not being really sure of himself, of looking to the addressee for confirmation, even of having no views of his own. This last criticism is, of course, one often levelled at women. One wonders how much of it reflects a use of language that has been imposed on women from their earliest years.

Related to this special use of a syntactic rule is a widespread difference perceptible in women's intonational patterns. ${ }^{4}$ There is a peculiar sentence intonation-pattern, found in English as far as I know only among women, which has the form of a declarative answer to a question, and is used as such, but has the rising inflection typical of a yes-no question, as well as being especially hesitant. The effect is as though one were seeking confirmation, though at the same time the speaker may be the only one who has the requisite information.

[4] For analogs outside of English to these uses of tag-questions and special intonationpatterns, cf. the discussion of Japanese particles in Lakoff (1972). It is to be expected that similar cases will be found in many other languages as well. See, for example, Haas' ( 1964 ) very interesting discussion of differences between men's and women's speech (mostly involving lexical dissimilarities) in many languages. 
(r3) (A) When will dinner be ready?

(B) Oh... around six o'clock...?

It is as though (B) were saying, 'Six o'clock, if that's OK with you, if you agree'. (A) is put in the position of having to provide confirmation, and (B) sounds unsure. Here we find unwillingness to assert an opinion carried to an extreme. One likely consequence is that these sorts of speech-patterns are taken to reflect something real about character and play a part in not taking a woman seriously or trusting her with any real responsibilities, since 'she can't make up her mind', and 'isn't sure of herself'. And here again we see that people form judgments about other people on the basis of superficial linguistic behavior that may have nothing to do with inner character, but has been imposed upon the speaker, on pain of worse punishment than not being taken seriously.

Such features are probably part of the general fact that women's speech sounds much more 'polite' than men's. One aspect of politeness is as we have just described: leaving a decision open, not imposing your mind, or views, or claims, on anyone else. Thus a tag-question is a kind of polite statement, in that it does not force agreement or belief on the addressee. A request may be in the same sense a polite command, in that it does not overtly require obedience, but rather suggests something be done as a favor to the speaker. An overt order (as in an imperative) expresses the (often impolite) assumption of the speaker's superior position to the addressee, carrying with it the right to enforce compliance, whereas with a request the decision on the face of it is left up to the addressee. (The same is true of suggestions - here, the implication is not that the addressee is in danger if he does not comply - merely that he will be glad if he does. Once again, the decision is up to the addressee, and a suggestion therefore is politer than an order.) The more particles in a sentence that reinforce the notion that it is a request, rather than an order, the politer the result. The sentences of (I4) illustrate these points: (14) (a) is a direct order; $(b)$ and (c) simple requests, and $(d)$ and $(e)$ compound requests. 5

(I4) (a) Close the door.

(b) Please close the door.

(c) Will you close the door?

(d) Will you please close the door?

(e) Won't you close the door?

Let me first explain why $(e)$ has been classified as a compound request. (A sentence like Won't you please close the door would then count as a doubly compound request.) A sentence like ( $\left.\mathrm{I}_{4}\right)(c)$ is close in sense to 'Are you willing to close the door?' According to the normal rules of polite conversation, to agree

[5] For more detailed discussion of these problems, cf. Lakoff (1972). 


\section{LANGUAGE AND WOMAN'S PLACE}

that you are willing is to agree to do the thing asked of you. Hence this apparent inquiry functions as a request, leaving the decision up to the willingness of the addressee. Phrasing it as a positive question makes the (implicit) assumption that a 'yes' answer will be forthcoming. Sentence (I4) $(d)$ is more polite than $(b)$ or $(c)$ because it combines them: Please indicating that to accede will be to do something for the speaker, and will you, as noted, suggesting that the addressee has the final decision. If, now, the question is phrased with a negative, as in (I4) (e), the speaker seems to suggest the stronger likelihood of a negative response from the addressee. Since the assumption is then that the addressee is that much freer to refuse, $\left(1_{4}\right)(e)$ acts as a more polite request than $\left(\mathrm{I}_{4}\right)(c)$ or $(d):(c)$ and $(d)$ put the burden of refusal on the addressee, as $(e)$ does not.

Given these facts, one can see the connection between tag questions and tagorders and other requests. In all these cases, the speaker is not committed as with a simple declarative or affirmative. And the more one compounds a request, the more characteristic it is of women's speech, the less of men's. A sentence that begins Won't you please (without special emphasis on please) seems to me at least to have a distinctly unmasculine sound. Little girls are indeed taught to talk like little ladies, in that their speech is in many ways more polite than that of boys or men, and the reason for this is that politeness involves an absence of a strong statement, and women's speech is devised to prevent the expression of strong statements.

\section{TALKING ABOUT WOMEN}

We have thus far confined ourselves to one facet of the problem of women and the English language: the way in which women prejudice the case against themselves by their use of language. But it is at least as true that others - as well as women themselves - make matters so by the way in which they refer to women. Often a word that may be used of both men and women (and perhaps of things as well), when applied to women, assumes a special meaning that, by implication rather than outright assertion, is derogatory to women as a group.

When a word acquires a bad connotation by association with something unpleasant or embarrassing, people may search for substitutes that do not have the uncomfortable effect - that is, euphemisms. Since attitudes toward the original referent are not altered by a change of name, the new name itself takes on the adverse connotations, and a new euphemism must be found. It is no doubt possible to pick out areas of particular psychological strain or discomfort - areas where problems exist in a culture - by pinpointing items around which a great many euphemisms are clustered. An obvious example concerns the various words for that household convenience into which human wastes are eliminated: toilet, bathroom, rest room, comfort station, lavatory, water-closet, loo, and all the others. 
In the case of women, it may be encouraging to find no richness of euphemism; but it is discouraging to note that at least one euphemism for 'woman' does exist, and is very much alive. The word, of course, is 'lady', which seems to be replacing 'woman' in a great many contexts. Where both exist, they have different connotations; where only one exists, there is usually a reason, to be found in the context in which the word is uttered.6

It may be objected at this point that lady has a masculine counterpart, namely gentleman, occasionally shortened to gent. But I don't think this is a fair comparison. Lady is much more common than gent(leman), and, since gent exists, the reason is not ease of pronunciation. Lady is really a euphemism for woman, but gentleman is not nearly frequent enough to classify as a euphemism for man. Just as we do not call whites 'Caucasian-Americans', there is no felt need to refer to men commonly as 'gentlemen'. And just as there is a need for such terms as 'Afro-Americans', there is similarly a felt need for 'lady'. One might even say that when a derogatory epithet exists, a parallel euphemism is deemed necessary.? To avoid having to resort to terms like 'Afro-American', we need only get rid of all expressions like 'nigger'; to banish 'lady' in its euphemistic sense from the vocabulary of English, we need only first get rid of 'broad' and its relations. But of course, as already pointed out, we cannot achieve this commendable simplification of the lexicon unless we somehow remove from our minds the idea that blacks are niggers, and that women are broads. The presence of the words is a signal that something is wrong, rather than (as too often interpreted by wellmeaning reformers) the problem itself. The point here is that, unless we start feeling more respect for women, and at the same time, less uncomfortable about

[6] Related to the existence of euphemistic terms for 'woman' is the existence of euphemistic terms for women's principal role, that of 'housewife'. Most occupational terms do not have coexisting euphemisms: these seem to come into being only when the occupation is considered embarrassing or demeaning. Thus there is no euphemism for 'professor', 'doctor', 'bank president'; but we do find 'mortician' and 'funeral director' for 'undertaker'; 'custodian' and 'sanitary engineer' for 'janitor'; 'domestic' for 'cleaning woman'; and so forth. Similarly one keeps running into hopeful suggestions, principally in the pages of women's magazines, that the lot of the housewife would be immeasurably improved if she thought of herself as 'homemaker', 'household executive', 'household engineer', or any of several others. I am not sure what to make of the fact that none of these (unlike those of the bona fide occupational euphemisms) have taken hold: is it because the 'housewife' doesn't consider her status demeaning? Then why the search for euphemisms? Or does she feel that there is no escape through a change in nomenclature, or lack pride in her job to such an extent that she doesn't feel up to making the effort? This is a question for the sociologist.

[7] The term WASP (white Anglo-Saxon Protestant) may occur to the reader as a possible derogatory term which has no parallel euphemism. But in fact, WASP is not parallel in usage to nigger, polack, or yid. One can refer to himself as a WASP, as one cannot refer to himself as a nigger without either a total lack of self-pride or bitter sarcasm. Thus one can say $(a)$, but probably not $(b)$, without special sarcastic inflection in the voice suggesting that it is an imitation of the addressee.

(a) Sure I'm a WASP, and proud of it!

(b) Sure I'm a nigger, and proud of it! 


\section{LANGUAGE AND WOMAN'S PLACE}

them and their roles in society in relation to men, we cannot avoid ladies any more than we can avoid broads. ${ }^{8}$

It might also be claimed that lady is no euphemism because it has exactly the same connotations as woman, is usable under the same semantic and contextual conditions. But a cursory inspection will show that this is not always the case. The decision to use one term rather than the other may considerably alter the sense of a sentence. The following are examples:

(15) (a) A (woman) that I know makes amazing things out of shoelaces (lady) and old boxes.

(b) A (woman) I know works at Woolworth's. (lady)

(c) A (woman) I know is a dean at Berkeley. (lady)

(These facts are true for some speakers of English. For others, lady has taken over the function of woman to such an extent that lady can be used in all these sentences.)

In my speech, the use of lady in (15) (c) imparts a frivolous, or nonserious tone to the sentence: the matter under discussion is one of not too great moment. In this dialect, then, lady seems to be the more colloquial word: it is less apt to be used in writing, or in discussing serious matters. Similarly in (15) (a), using lady would suggest that the speaker considered the 'amazing things' not to be serious art, but merely a hobby or an aberration. If woman is used, she might be a serious (pop art) sculptor.

Related to this is the use of lady in job terminology. For at least some speakers, the more demeaning the job, the more the person holding it (if female, of course) is likely to be described as a lady. Thus, cleaning lady is at least as common as cleaning woman, saleslady as saleswoman. But one says, normally, woman doctor. To say lady doctor is to be very condescending: it constitutes an insult. For men, there is no such dichotomy. Garbage man or salesman is the only possibility, never

[8] In the past, some ethnic groups that today are relatively respectable were apparently considered less so. And in looking at reports of the terms used to describe those groups at the earlier time, we find two interesting facts: first, there is a much greater incidence of derogatory epithets for that group (as might be expected); and second (which one might not be led to expect automatically) there exist euphemistic terms for that group that are no longer in general use. One can only conclude that euphemisms vanish as they are no longer needed. The example I have in mind is that of the words used to describe Jews. Aside from the uncomplimentary epithets which still exist today, though not encountered very often, one finds, in reading novels written and set more than half a century ago, a number of euphemisms that are not found any more, such as 'Hebrew gentleman' and 'Israelite'. The disappearance of the euphemisms concurrently with the derogatory terms suggests that women will be ladies until some more dignified status can be found for them. 
*garbage gentleman. And of course, since in the professions the male is unmarked, we never have * man (male) doctor.

Numerous other examples can be given, all tending to prove the same point: that if, in a particular sentence, both woman and lady might be used, the use of the latter tends to trivialize the subject matter under discussion, often subtly ridiculing the woman involved. Thus, for example, a mention in the San Francisco Chronicle of January 31 1972, of Madalyn Murray O'Hair as the 'lady atheist' reduces her position to that of scatterbrained eccentric, or at any rate, one who need not be taken seriously. Even woman atheist is scarcely defensible: first, because her sex is irrelevant to her philosophical position, and second, because her name makes it clear in any event. But lady makes matters still worse. Similarly a reference to a woman sculptor, is only mildly annoying (since there is no term *male sculptor, the discrepancy suggests that such activity is normal for a man, but not for a woman), but still it could be used with reference to a serious artist. Lady sculptor, on the other hand, strikes me as a slur against the artist, deliberate or not, implying that the woman's art is frivolous, something she does to fend off the boredom of suburban housewifery, or at any rate, nothing of moment in the art world. Serious artists have shows, not dilettantes. So we hear of onewoman shows, but never one-lady shows.

Another realm of usage in which lady contrasts with woman is in titles of organizations. It seems that organizations of women who have a serious purpose (not merely that of spending time with one another) cannot use the word lady in their titles, but less serious ones may. Compare the Ladies' Auxiliary of a men's group, or the Thursday Evening Ladies Browning and Garden Society with *Ladies' Lib or *Ladies Strike for Peace.

What is curious about this split is that lady is as noted in origin a euphemism for woman. What kind of euphemism is it that subtly denigrates the people to whom it refers, suggests that they are not to be taken seriously, are laughingstocks? A euphemism, after all, is supposed to put a better face on something people find uncomfortable. But this is not really contradictory. What a euphemism is supposed to do, actually, is to remove from thought that part of the connotations of a word that creates the discomfort. So each of the euphemisms for toilet, starting with toilet, seems to be trying to get further from the notion of excrement, by employing successively more elegant terminology that seems designed to suggest that piece of furniture in question has really other primary uses, for performing one's toilette, for washing, for comfort, for resting, but never for those other things. Perhaps the notion of the non-seriousness of women is not the thing that makes men - the devisers of euphemism - as well as women uncomfortable. Perhaps it is some other aspect of the man-woman relationship. How can we determine whether this is in fact the case?

One way of identifying the precise source of discomfort is, perhaps, by looking at the derogatory terms for something. Many of the terms for blacks refer to 
their physical characteristics. And the latest euphemism for blacks, AfroAmericans, seems to be a specific attempt to get away from color-names. (The term black is not a euphemism, but rather an attempt to confront the issue squarely and make color into a source of pride.) And as has often been noted, derogatory terms for women are very often overtly sexual: the reader will have no difficulty recalling what $I$ allude to here. Perhaps the way in which lady functions as a euphemism for woman is that it does not contain the sexual implications present in woman: it is not 'embarrassing' in that way. If this is so, we may expect that, in the future, lady will replace woman as the primary word for the human female, since woman will have become too blatantly sexual. That this distinction is already made in some contexts at least is shown in the following examples:9

[9] The distinction between lady and woman, in those dialects of American English in which it is found, may be traceable to other causes than the sexual connotations present in woman. Most people who are asked why they have chosen to use lady where woman would be as appropriate will reply that lady seemed more polite. The concept of politeness thus invoked is the politeness used in dignifying or ennobling a concept that normally is not thought of as having dignity or nobility. It is this notion of politeness that explains why we have cleaning lady, but not, normally, lady doctor: a doctor does not need to be exalted by conventional expressions: she has dignity enough from her professional status. But a cleaning woman is in a very different situation, in which her occupational category requires ennobling. Then perhaps we can say that the very notion of womanhood, as opposed to manhood, requires ennobling since it lacks inherent dignity of its own: hence the word woman requires the existence of a euphemism like lady. Besides or possibly because of being explicitly devoid of sexual connotation lady carries with it overtones recalling the age of chivalry: the exalted stature of the person so referred to, her existence above the common sphere. This makes the term seem polite at first, but we must also remember that these implications are perilous: they suggest that a 'lady' is helpless, and cannot do things for herself. In this respect the use of a word like lady is parallel to the act of opening doors for women - or ladies. At first blush it is flattering: the object of the flattery feels honored, cherished, and so forth; but by the same token, she is also considered helpless and not in control of her own destiny. Women who protest that they like receiving these little courtesies, and object to being liberated from them, should reflect a bit on their deeper meaning and see how much they like that.

This brings us to the consideration of another common substitute for woman, namely girl. One seldom hears a man past the age of adolescence referred to as a boy, save in expressions like 'going out with the boys', which are meant to suggest an air of adolescent frivolity and irresponsibility. But women of all ages are 'girls': one can have a man, not a boy, Friday, but a girl, never a woman or even a lady, Friday; women have girl friends, but men do not - in a nonsexual sense - have boy friends. It may be that this use of girl is euphemistic in the sense in which lady is a euphemism: in stressing the idea of immaturity, it removes the sexual connotations lurking in woman. Instead of the ennobling present in lady, girl is (presumably) flattering to women because of its stress on youth. But here again there are pitfalls: in recalling youth, frivolity and immaturity, girl brings to mind irresponsibility : you don't send a girl to do a woman's errand (or even, for that matter, a boy's errand). It seems that again, by an appeal to feminine vanity (about which we shall have more to say in a later footnote), the users of English have assigned women to a very unflattering place in their minds: a woman is a person who is both too immature and too far from real life to be entrusted with responsibilities and with decisions of any serious nature. Would you elect president a 
(I6) (a) She's only twelve, but she's already a woman.

*lady

(b) After ten years in jail, Harry wanted to find a woman.

$$
\text { *lady }
$$

(c) She's my woman, see, so don't mess around with her.

*lady

It may be, finally, that the reason the use of lady rather than woman in a sentence creates the impression of frivolity discussed above precisely because of the euphemistic nature of lady. In serious discussion, one does not typically employ euphemisms. So, for instance, a sentence like ( $\mathrm{I}_{7}$ ) is more suited to cocktail party chitchat by returning tourists than learned discussion by anthropologists.

(17) When the natives of Mbanga want to use the little boys' room, first they find a large pineapple leaf...

Perhaps the discomfort men suffer in contemplating, more or less unconsciously, the sexuality of women is traceable to guilt feelings on their part. The guilt arises, I should think, not only because they think sex is inherently dirty (that is another problem) but because if one deals with women as primarily sexual beings, one is in effect automatically relegating them to object status; if women are there for the use and enjoyment of men, they are not fully human beings in their own right. But women are, in most other respects evidently human. So a man feels somewhat ambivalent - more or less consciously - and reacts all the more strongly for that reason. Hence, perhaps, the rather hysterical ridicule heaped on Women's Lib in the media. In any case, throughout English one finds evidence of many sorts that women are viewed (by women as well as men) as secondary beings: as having an existence only when defined by a man. Sociologically it is probably fairly obvious that a woman in most subcultures in our society achieves status only through her father's, husband's, or lover's position. What is remarkable is that these facts show up linguistically in nonobvious ways. ${ }^{10}$

person incapable of putting on her own coat? (Of course, if we were to have a married woman president, we would not have any name for her husband parallel to First Lady: and why do you suppose that is?)

[ro] These facts about women's position should cause us to question one of the commonest criticisms made of women's behavior, as opposed to men's: one often hears that women are vain and self-centered, concerned only about their appearance and how others view them. A little thought should convince anyone that, in fact, it is men who are self-centered and egocentric, and that women's seeming vanity is not that at all.

As noted above, a woman's reputation and position in society depend almost wholly on the impression she makes upon others, how others view her. She must dress decoratively, look attractive, be compliant, if she is to survive at all in the world. Then her 


\section{LANGUAGE AND WOMAN'S PLACE}

Suppose we take a pair of words which, in terms of the possible relationships in an earlier society, were simple male-female equivalents, analogous to bull: cow. Suppose we find that, for independent reasons, society has changed in such a way that the primary meanings now are irrelevant. Yet the words have not been discarded, but have acquired new meanings, metaphorically related to their original senses. But suppose these new metaphorical uses are no longer parallel to each other. By seeing where the parallelism breaks down, we can intuit something about the different roles played by men and women in this culture. One good example of such a divergence through time is found in the pair, master and mistress. Once used with reference to one person's power over another, these words became unusable in their original sense as the master-servant relationship became nonexistent. But the words are still common, used as in the sentences of (I8) and (I9):

(18) (a) He is a master of the intricacies of academic politics.

(b) *She is a mistress ...

(19) (a) *Harry declined to be my master, and so returned to his wife.

(b) Rhonda declined to be my mistress, and so returned to her husband.

Unless used with reference to animals or slaves, master now generally refers to a man who has acquired consummate ability in some field, normally non-sexual, But its feminine counterpart cannot be used in this way. It is practically restricted to its sexual sense of 'paramour'. We start out with two terms, both roughly paraphrasable as 'one who has power over another'. But the masculine form, once one person is no longer able to have absolute power over another, becomes usable metaphorically in the sense of 'have power over something'. The feminine counterpart also acquired a metaphorical interpretation, but the metaphor here

overattention to appearance and appearances (including, perhaps overcorrectness and overgentility of speech and etiquette) is merely the result of being forced to exist only as a reflection in the eyes of others. She does not, cannot, do anything in her own behalf or purely for her own pleasure or aggrandizement. (Rather ironically, the only way she can increase her own comfort, pleasure, and security is through her husband's advancement, and thus she can only achieve material comforts through someone else's efforts. What seem to be self-centered efforts are really aimed at the opinions of others, and what appear to be efforts for someone else are really the only ones permissible for a woman's own behalf. It is no wonder women lack an identity and feel they have no place of their own.)

In fact, men are the vain sex. Men may derive pleasure directly from their own works. Men do things purely for their own satisfaction, not caring nearly so much how it will look to others. This, surely, is the true egocentricity. Further, it seems to me that the ultimate vanity or self-centeredness is to be found in eccentricity: the eccentric alone truly cares only for himself and his own pleasure: he does not concern himself with how his actions affect others or look to others. And eccentricity is far more common and far more tolerated in men than in women. A strong personality in general, a mark of egocentricity, is again valued in men much more than in women. For these reasons, women are not very successful in business or politics, where both vanity and eccentricity of certain sorts can be marks of distinction rather than objects of ridicule. 
is sexual: one's mistress 'has power over' one in a sexual sense. And this expression is probably chivalrous, rather than descriptive of the real-world relationship between lovers: in terms of choice, of economic control, and so forth, it is generally the man who holds the power in such a relationship; to call a woman one's 'mistress' is the equivalent of saying 'please' in prefacing a request to a subordinate: both are done for politeness, and are done purely because both participants in the relationship, in both cases, know that the supposed inferiority of the mistress' lover and of the user of 'please' is only a sham. Interesting too in this regard is the fact that 'master' requires as its object only the name of some activity, something inanimate and abstract. But 'mistress' requires a masculine noun in the possessive to precede it. One cannot say:

(20) *Rhonda is a mistress.

One must be someone's mistress. 11 So here we see several important points concerning the relationship between men and women illustrated: first, that men are defined in terms of what they do in the world, women' in terms of the men with whom they are associated; and second, that the notion of 'power' for a man is different from that of 'power' for a woman: it is acquired and manifested in different ways. One might say then that these words have retained their principal meanings through time; what has changed are the kinds of interpersonal relationships they are used to refer to.

As a second example, the examples in (2I) should be completely parallel semantically.

(2I) (a) He's a professional.

(b) She's a professional.12

[II] And obviously too, it is one thing to be an old master, like Hans Holbein, and another to be an old mistress: the latter, again, requires a masculine possessive form preceding it, indicating who has done the discarding. Old in the first instance refers to absolute age: the artist's lifetime vs. the time of writing. But old in the second really means 'discarded', 'old' with respect to someone else.

Others, too, have been struck by the hidden assumptions in the word mistress. In an article on the Op-Ed page of the New York Times, July 20 1972, Rebecca Reyher suggests that a way around this difficulty is to adopt a parallel term for the man in such a relationship: stud. But further thought will make it clear that the use of this new term will not obviate the problem: the roots lie deeper, in the social nature of the relationship itself. As long as it is the woman who is dependent on the man, socially and economically, in such relationships, there will be no possibility of coining a parallel term for mistress. Just as we will have the sorts of disparities illustrated by sentences (I8)-(i g), we will find further disparities, like the difference in the acceptability of $(a)$ and $(b)$ below, for the same reasons.

(a) He's a real stud!

(b) *She's a real mistress!

[12] This discrepancy is not confined to English. Victor Wen has informed me that a similar situation pertains in Chinese. One may say of a man, 'He's in business', and of a woman, 'she's in business', lexically and grammatically parallel. The former means about what its English equivalent means. But the latter is synonymous to sentence (2I) $(b)$. 


\section{LANGUAGE AND WOMAN'S PLACE}

Hearing and knowing no more about the subjects of the discourse than this, what would one assume about them in each case? Certainly in (a) the normal conclusion the casual eavesdropper would come to was that 'he' was a doctor or a lawyer, or a member of one of the other professions. But it is much less likely that one would draw a similar conclusion in $(b)$. Rather, the first assumption most speakers of English seem to make is that 'she' is a prostitute, literally or figuratively speaking. Again, a man is defined in the serious world by what he does, a woman by her sexuality, that is, in terms of one particular aspect of her relationship to men.13

The sexual definition of women, however, is but one facet of a much larger problem. In every aspect of life, a woman is identified in terms of the men she relates to. The opposite is not usually true of men: they act in the world as autonomous individuals, but women are only 'John's wife', or 'Harry's girl friend'. Thus, meeting a woman at a party, a quite normal opening conversational gambit might be, 'What does your husband do?' One very seldom hears, in a similar situation, a question addressed to a man, 'What does your wife do?' The question would, to a majority of men, seem tautological: 'She's my wife - that's what she does'. This is true even in cases where a woman is being discussed in a context utterly unrelated to her relationships with men, when she has attained sufficient stature to be considered for high public office. In fact, in a recent discussion of possible Supreme Court nominees, one woman was mentioned prominently. In discussing her general qualifications for the office, and her background, the New York Times saw fit to remark on her 'bathing-beauty figure'. Note that this is not only a judgment on a physical attribute totally removed from her qualifications for the Supreme Court, but that it is couched in terms of how a man would react to her figure. Some days later, President Nixon announced the nominations to his Price Board, among them one woman. In the thumbnail sketches The Times gave of each nominee, it was mentioned that the woman's husband was a professor of English. In the case of none of the other nominees was the existence of a spouse even hinted at, and much less was there any clue about the spouse's occupation. So here, although the existence of a husband was as irrelevant for this woman appointee as the existence of a wife was for any of the male appointees, the husband was mentioned, since a woman cannot be placed in her position in society by the readers of The Times unless they know her marital status. The same is not at all true of men. Similarly in the

[13] James Fox tells me that, in many cultures as in English, people may be referred to metaphorically by animal-names, suggesting that they have some of the attributes of that animal, real or part of the folklore. What is interesting here is that, where animal names may be applied to both men and women - whether or not there are separate terms for male and female in the animal, the former may have connotations in all sorts of areas, while the latter, whatever other connotations the term may suggest, nearly always makes sexual reference as well. Compare in this regard dog and bitch, fox and vixen, and the difference between he's a pig and she's a pig. 
recent mayoral campaign in San Francisco, the sole woman candidate was repeatedly referred to as Mrs Feinstein, never Feinstein, when her opponents were regularly referred to by first and last names or last names alone: Foseph Alioto, or Alioto, not $\mathrm{Mr}$ Alioto. Again, the woman had to be identified by her relationship to a man, although this should bear no relevance to her qualifications for public office. 14

Also relevant here are the connotations (as opposed to the denotative meanings) of the words spinster and bachelor. Denotatively, these are, again, parallel to 'cow' versus 'bull': one is masculine, the other feminine, and both mean, 'one who is not married'. But there the resemblance ends. Bachelor is at least a neutral term, often used as a compliment. Spinster normally seems to be used pejoratively, with connotations of prissiness, fussiness, and so on. Some of the differences between the two words are brought into focus in the following examples.

(22) (a) Mary hopes to meet an eligible bachelor.

(b) *Fred hopes to meet an eligible spinster.

It is the concept of an eligible spinster that is anomalous. If someone is a spinster, by implication she is not eligible (to marry); she has had her chance, and been passed by. Hence, a girl of twenty cannot be properly called a spinster: she still has a chance to be married. ${ }^{15}$ But a man may be considered a bachelor as soon as he reaches marriageable age: to be a bachelor implies that one has the choice of marrying or not, and this is what makes the idea of a bachelor existence attractive, in the popular literature. He has been pursued and has successfully eluded his pursuers. But a spinster is one who has not been pursued, or at least not seriously. She is old unwanted goods. Hence it is not surprising to find that a euphemism has arisen for spinster, a word not much used today, bachelor girl, which attempts to capture for the woman the connotations bachelor has for a man. But this, too, is not much used except by writers trying to give their (slick magazine) prose a 'with-it' sound. I have not heard the word used in unselfconscious speech. Bachelor, however, needs no euphemisms.

When bachelor and spinster are used metaphorically, the distinction in connotation between the two becomes even clearer.

(23) (a) John is a regular bachelor.

(b) Mary is a regular spinster.

[14] While sharp intellect is generally considered an unqualified virtue in a man, any character trait that is not related to a woman's utility to men is considered suspect, if not downright bad. Thus the word brainy is seldom used of men; when used of women it suggests ( $\mathrm{I}$ ) that this intelligence is unexpected in a woman; (2) that it isn't really a good trait. If one calls a woman 'smart', outside of the sense of 'fashionable', one either means it as a compliment to her domestic thrift and other housekeeping abilities, or again, it suggests a bit of wariness on the part of the speaker.

[I5] Of course, spinster may be used metaphorically in this situation, as described below. 
The metaphorical connotations of 'bachelor' generally suggest sexual freedom; of 'spinster', puritanism or celibacy. So we might use a sentence like (23) (a) if John was in fact married but engaged in extramarital affairs freely. It is hard to think of other circumstances in which it might be used. Certainly it could not be used if John were married but determined to remain celibate. (23) $(b)$, on the other hand, might be used under two conditions: first, if Mary were in fact unmarried, but still of marriageable age (that is, not yet a literal spinster), and very cold and prissy; secondly, if Mary were married, with the same characteristics. The use of 'regular', then seems to be an indicator that the noun it modifies is to be taken purely in its connotative, rather than denotative sense.

These examples could be multiplied. It is generally considered a faux pas, in proper society, to congratulate a girl on her engagement, while it is correct to congratulate her fiancé. Why is this? The reason here seems to be that it is impolite to remind someone of something that may be uncomfortable to him. To remind a girl that she must catch someone, that perhaps she might not have caught anyone, is rude, and this is what is involved, effectively, in congratulating someone. To congratulate someone is to rejoice with him in his good fortune; but it is not quite nice to remind a girl that getting married is good fortune for her, indeed a veritable necessity; it is too close to suggesting the bad fortune that it would be for her had she not found someone to marry. In the context of this society's assumptions about women's role, to congratulate a girl on her engagement is virtually to say, 'Thank goodness! You had a close call!' For the man, on the other hand, there was no such danger. His choosing to marry is viewed as a good thing, but not something essential, and so he may be congratulated for doing a wise thing. If man and woman were equal in respect to marriage, it would be proper either to congratulate both, or neither.

Another thing to think about is the traditional conclusion of the marriage service: 'I now pronounce you man and wife.' The man's position in the world, and in relation to other people including the bride, has not been changed by the act of marriage. He was a 'man', before the ceremony, and a 'man' he still is (one hopes) at its conclusion. But the bride went into the ceremony a 'woman', not defined by any other person, at least linguistically: she leaves it a 'wife', defined in terms of the 'man', her husband. There are many other aspects of traditional marriage ceremonies in our culture that might be used to illustrate the same point.

And, having discussed bachelorhood and spinsterhood, and the marital state, we arrive at widowhood. Surely a bereaved husband and a bereaved wife are equivalent: they have both undergone the loss of a mate. But in fact, linguistically at any rate this is not true. It is true that we have two words, widow and widower; but here again, widow is far commoner in use. Widows, not widowers, have their particular roles in folklore and tradition, and mourning behavior of particular 
sorts seems to be expected more strongly, and for a longer time, of a widow than of a widower. But there is more than this, as evidenced by the following:

(24) (a) Mary is John's widow.

(b) *John is Mary's widower.

Like mistress, widow commonly occurs with a possessive preceding it, the name of the woman's late husband. Though he is dead, she is still defined by her relationship to him. But the bereaved husband is no longer defined in terms of his wife. While she is alive, he is sometimes defined as Mary's husband (though less often, probably, than she is as 'John's wife'). But once she is gone, her function for him is over, linguistically speaking anyway. So once again, we see that women are always defined in terms of the men to whom they are related, and hence the worst thing that can happen to a woman is not to have a man in this relationship that is, to be a spinster, a woman with neither husband nor lover, dead or alive.

What all these facts suggest is merely this, again: that men are assumed to be able to choose whether or not they will marry, and that therefore their not being married in no way precludes their enjoying sexual activity; but if a woman is not married, it is assumed to be because no one found her desirable; hence if a woman is not married by the usual age, she is assumed to be sexually undesirable, prissy, and frigid.

The reason for this distinction seems to be found in the point made earlier: that women are given their identities in our society by virtue of their relationship with men, not vice versa. ${ }^{16}$

Now it becomes clearer why there is a lack of parallelism in men's and women's titles. To refer to a man as $M r$ does not identify his marital status; but there is no such ambiguous term for women: one must decide on Mrs or Miss. To remedy this imbalance, a bill was proposed in the United States Congress by

[16] It has been argued that this claim about disparities in use between man/husband and woman/wife, as well as bachelor/spinster and widow/widower, does not apply in other languages, where they are not found, although otherwise the speakers of these languages are as sexist as any. Then, the argument continues, aren't these so-called 'proofs' of linguistic sexism invalidated, in the face of, e.g. French mari et ferme = 'husband and woman'? Or in the face of the fact that widower is not morphologically marked vis-di-vis widow, in many languages?

My answer to all these arguments is no. We must look at the total picture, not its individual parts. Perhaps the French speaker says 'mari et femme'; can a female speaker of French say, 'mon mari travaille'? Only if she can (and if a large body of the other claims made here are invalidated in French) can we claim that the linguistic disparity between 'man' and 'woman' does not hold in French.

Further, it should be clear that the presence of a marked trait (like the special ending on the masculine widower) is linguistic evidence of a social disparity; but the absence of such a trait is not evidence of its opposite. A language generally makes a distinction, or utilizes a marked form, for a reason; but the lack of such marking may be mere accident. Obviously, any fairly inventive mind, given fifteen minutes, could poirst to a dozen uses in English that are not sexist, but might conceivably have been so; but no one will use these non-occurrences as proof of the non-sexism of English. 
Bella Abzug and others that would legislate a change in women's titles: Miss and Mrs would both be abolished in favor of Ms. Rather less seriously, the converse has been proposed by Russell Baker, that two terms should be created for men, $M r m$ and Srs depending upon marital status. We may ask several questions: $(a)$ Why does the imbalance exist in the first place? $(b)$ Why do we feel that Baker's suggestion (even if it did not come from Baker) is somehow not to be taken as seriously as Abzug's? And (c) Does Abzug's proposal have a chance of being accepted in colloquial speech?17

(a) A title is devised and used for a purpose: to give a clue to participants in social interaction how the other person is to be regarded, how he is to be addressed. In an avowedly class-conscious society, social ranking is a significant determining factor: once you know that your addressee is to be addressed as 'lord', or 'mister', or 'churl', you know where he stands with respect to you: the title establishes his identity in terms of his relationship with the larger social group. For this reason, the recent suggestion that both $M r$ and Mrs/Miss be abolished in favor of Person is unlikely to be successful: Person tells you only what you already know, and does not aid in establishing ranking or relationship between two people. Even in a supposedly classless society, the use of $M r$ (as opposed to simple last name or first name) connotes a great deal about the relationship of the two participants in the discourse with respect to each other. 'To introduce yourself, 'I'm Mr Jones' puts the relationship you are seeking to establish on quite a different basis than saying, 'I'm Jones', or 'I'm John', and each is usable under quite different contextual conditions, socially speaking. As long as social distinctions, overt or covert, continue to exist, we will be unable to rid our language of titles that make reference to them. It is interesting that the French and Russian revolutions both tried to do away with honorific titles that distinguished class by substituting 'citizen(ess)' and 'comrade'. These, however, are not purely empty like 'person': they imply that speaker and addressee share a relationship in that both are part of the state, and hence by implication, both equal. In France, the attempt was not long-lived. (Although tovarishch is normal today in the Soviet Union, I don't know whether it is really usable under all conditions, whether a factory worker, for instance, could use it to his foreman, or his foreman's wife.)

Although, in our society, naming conventions for men and women are essentially equal (both have first and last names, and both may have additional names, of lesser importance), the social conventions governing the choice of form of address is not parallel in both sexes. Thus, as noted, a man, $\mathrm{Mr}$ John Jones, may be addressed as John, as Jones, as Mr Jones, and as Mr John Jones. The

[17] One must distinguish between acceptance in official use and documents (where Ms is already used to some extent) and acceptance in colloquial conversation, where I have never heard it. I think the latter will be a long time in coming, and I do not think we can consider Ms a real choice until this occurs. 
first normally implies familiarity, the second intimacy coupled with Jones's inferiority (except in situations of non-direct address, as in professional citation; or among intimates, as a possibly more-intimate form of address even than first name alone, without inferiority being implied); the third distance and more or less equality. The last is never used in direct address, and again indicates considerable distance. To address someone by first name alone is to assume at least equality with the other person, and perhaps superiority (in which case the other person will respond with $M r$ and last name). $M r$ fones is probably the least-marked form of address, a means of keeping distance with no necessary suggestions of status. To address someone as fones socially or in business may be an indication of his inferior status, but to refer to someone that way professionally (as at a linguistics conference, generally in indirect reference rather than direct address) seems to be a mark of his acceptance, as a colleague and a person to be taken seriously as a fellow member of the profession. In this way, perhaps, it is related to the last-name-only of familiarity: it is 'we know each other well, we are equals and pals, or equals and colleagues'.

Possibly related to this is a discrepancy in the rules of professional naming. Among linguists, at any rate, there are rules, unwritten but generally understood, about when someone is referred to (orally in discussion, rather than cited in papers) by full name, by last name, by title (Dr, Professor, Mr) plus last name. If one is speaking of a student, or of a close friend to someone else who, the speaker knows, is also a friend of the person referred to, and the name is unambiguous in context, the reference is often, though not necessarily, by first name, though one also hears last names if the person referred to is male: either Fred or Smith may be used to refer to Fred Smith under these circumstances. If the person is less well-known, and therefore not considered somehow a full colleague, the reference is most often by full first and last name; $a$ paper by Smith's student, Bill Snurd, not *Snurd. (Any title alone with either last or firstand-last name either indicates that the speaker himself is not a full member of the club, or that he considers the person referred to beyond the professional pale: 'Gosh, I talked to Professor Chomsky!' is the effusion of a neophyte.) All of this suggests a kind of understood camaraderie among people who are understood to 'belong', and may act as a covert means of screening out non-members. Then what of the women in the profession (who, we will recall, are not professionals)? One finds oneself more and more often in awkward situations, as women become more prevalent in the field, and one does not know how to refer to them appropriately. If we are in a situation in which first-name alone might be used of a male linguist, we are in no trouble: first-name alone is used of a woman as well. If we are in a situation where first-plus-last name is used of a man, this will also be used for a woman, with no trouble. But there is a shadow area: if someone is assumed to be an equal and a colleague, but either the speaker is not really a personal friend, or he knows the addressee is not, or he merely 
wishes to keep the conversation on a strictly impersonal note. Here, if the person referred to is a man, we normally find last-name-alone used. But for a woman, this is much less common. ( $\mathrm{I}$ am, again, not referring to citation in writing, where last-name-alone is common for women as well as men.) There are two ways out: first-name alone (e.g. Jane), or both names (e.g. Jane Jones), and I have encountered both, while I have virtually never encountered last-name alone (e.g. Jones) for women. But the use of the first name alone, in situations in which it is not warranted, such as if the speaker really is not personal friends with the person referred to, sounds patronizing, and the second awkward in suggesting that the person referred to is not accepted as a colleague. Yet these are the only normal options. 18 It would seem as though male members of the profession are, subconsciously or otherwise, loath to admit women to full membership in their club, and this trouble in terms of address - limiting the choice to either addressing a woman by first name, in this situation implying her inferiority to the speaker, or by both names, suggesting she is not quite a full colleague - is symptomatic of deeper problems of which we are all aware. ${ }^{19}$

Aside from making apparent a dilemma arising from a social inequity, the facts noted above are of interest for other reasons: they show that titles are very much alive in our supposedly classless society, and apparently small differences

[18] I am speaking here only of prevailing tendencies. Exceptions obviously exist, and are the more apt to be made the better known a woman is in her field. But certainly, in common conversational use among linguists speaking colloquially, we might expect to find sentence $(a)$ below rather more than we might expect $(b)$.

Say, what did you think of Lakoff's latest paper, where $(a)$ he

(b) she

makes the claim that logical structure is to be formally thought of as a 100-lb. purple orangutan?

Ordinarily, the hearer of the sentence above would be somewhat jarred by encountering the feminine pronoun later in the sentence, since last-name-alone sets up a strong assumption that it is a male colleague being referred to. Probably the majority of linguists, in this situation, would also resort to circumlocution to avoid the following sentence:

(c) I understand Green is claiming that Morgan thinks with a fork.

[19] I think this tendency to use first names sooner and be more apt to use them, rather than last-name-alone or title-plus-last-name, in referring to and addressing women, is evident in other areas than academia. On television discussion shows, or commentary, or topical comedy (of the Bob Hope kind), a woman will be called or referred to by her first name where a man might not. Again, this is not a hard-and-fast rule, but depends upon the respect accorded to the woman due to her age, position, and attractiveness: it seems as though the more attractive a woman is, the less she can be taken seriously, and the more she is considered a decoration, able to be addressed by first-name-only. I feel that, other things being equal, there is a greater likelihood of hearing Gloria Steinem called 'Gloria' by someone who does not know her very well, than of hearing Norman Mailer called 'Norman' under the same conditions. (Of course, nobody is likely to call the Prime Minister of Israel 'Golda'.) This usage is perhaps to be compared with the tradition of calling children freely by their first names, and may be parallel to the use of 'girl' for 'woman' discussed in an earlier footnote. 


\section{LANGUAGE IN SOCIETY}

in their use reflect great chasms in social position among users. The use (or misuse) of titles supplies much information to people, and hence titles are important in our language as in our society, and not about to be lightly discarded.

If then, we can reasonably assume that a title supplies information about the person to whose name it is attached, we may further assume that this information is necessary in telling people how to interact with this person. And if this sort of information is felt to be necessary for one class of people and not another, we may expect to find a distinction made in the titles for the first class, if at all, but not the second.

So it is with $M r s, M i s s$, and $M r$. Since a significant part of the opinion one normally forms about a woman's character and social station depends on her marital status - as is not the case with men - it is obvious that the title of address should supply this information in the case of women, but not of men.20 Once again, it would seem that trying to legislate a change in a lexical item is fruitless. The change to $M s$ will not be generally adopted until women's status in society changes to assure her an identity based on her own accomplishments. ${ }^{21}$ (Perhaps even more debasing than the Mrs/Miss distinction is the fact that the woman in marrying relinquishes her own name, while the man does not. This suggests

[20] It may seem as though a man's marital status is, under certain conditions, of crucial interest to a woman, and therefore this point is suspect. But I think we have to distinguish between importance in the eyes of a single person in a particular situation, and importance in the eyes of society at large, in a great many possible situations. At almost every turn, because of the way social and business events are arranged, one needs to know a woman's marital status, and the position held by her husband. But one does not need the same information about a man, since his social status can be gauged, generally, purely by reference to his own accomplishments.

[21] Although blacks are not yet fully accorded equal status with whites in this society, nevertheless black, a term coined to elicit racial pride and sense of unity, seems to have been widely adopted both by blacks and whites, both in formal use and in the media, and increasingly in colloquial conversation. Does this constitute a counterexample to my claim here? I think not, but rather an element of hope. My point is that linguistic and social change go hand-in-hand: one cannot, purely by changing language use, change social status. The word black, in its current sense, was not heard until the late r 960 's or even 1970, to any significant extent. I think if its use had been proposed much earlier, it would have failed of acceptance. I think the reason people other than blacks can understand and sympathize with black racial pride is that they were made aware of the depths of their prejudice during the civil-rights struggles of the early r 960 . It took nearly ten years from the beginning of this struggle for the use of black to achieve wide acceptance, and it is still often used a bit self-consciously, as though italicized. But since great headway was made first in the social sphere, linguistic progress could be made on that basis; and now, this linguistic progress, it is hoped, will lead to new social progress in turn. The women's movement is but a few years old, and has, I should think, much deeper ingrained hostility to overcome than the civil rights movement ever did. (Among the intelligentsia, the black civil rights struggle was never a subject for ridicule, as women's liberation all too often is, among those very liberals who were the first on their blocks to join the NAACP.) The parallel to the black struggle should indicate that social change must precede lexical change: women must achieve some measure of greater social independence of men before Ms can gain wider acceptance. 
even more firmly that woman is her husband's possession, having no other identity than that of his wife. Not only does she give up her last name [which, after all, she took from her father], but often her first name as well, to become Mrs Fohn Smith.)

(b) There is thus a very good reason why a distinction is made in the case of women, but not men, in the matter of marital status. But this fact suggests an answer to the second question posed above, regarding why $M s$ is felt to be a more serious proposal than Baker's suggestion. It is obviously easier to imagine obliterating an extant distinction than creating a new one: easier to learn to ignore the marital status of a woman than to begin to pay attention to that of a man. Moreover, we may also assume that for a woman, the use of $M s$ is a liberating device, one to be desired. But (as Baker suggests) the use of two titles for men is an encumbrance, a remover of certain kinds of liberties, and something definitely undesirable. So the two suggestions are not equivalent, and if either were ever to be accepted, the choice of $M s$ is the probable candidate.

(c) The third question regarding the chances $M s$ has for real acceptance, has, in effect, already been answered. Until society changes so that the distinction between married and unmarried women is as unimportant in terms of their social position as that between married and unmarried men, the attempt in all probability cannot succeed. Like the attempt to substitute any euphemism for an uncomfortable word, the attempt to do away with Miss and Mrs is doomed to failure if it is not accompanied by a change in society's attitude to what the titles describe.

\section{SUGGESTIONS AND CONCLUSIONS}

Linguistic imbalances are worthy of study because they bring into sharper focus real-world imbalances and inequities. They are clues that some external situation needs changing, rather than items that one should seek to change directly. A competent doctor tries to eliminate the germs that cause measles, rather than trying to bleach the red out with peroxide. I emphasize this point because it seems to be currently fashionable to try, first, to attack the disease by attempting to obliterate the external symptoms; and, secondly, to attack every instance of linguistic sexual inequity, rather than selecting those that reflect a real disparity in social treatment, not mere grammatical nonparallelism; we should be attempting to single out those linguistic uses that, by implication and innuendo, demean the members of one group or another, and should be seeking to make speakers of English aware of the psychological damage such forms do. The problem, of course, lies in deciding which forms are really damaging to the ego, and then in determining what to put in their stead.

A good example, which troubles me a lot at present, is that of pronominal neutralization. In English, as indeed in the great majority of the world's languages, 


\section{LANGUAGE IN SOCIETY}

when reference is made individually to members of a sexually mixed group, the normal solution is to resolve the indecision as to pronoun choice in favor of the masculine:22 the masculine, then, is 'unmarked' or 'neutral', and therefore will be found referring to men and women both in sentences like the following:

(25) (a) Everyone take his seat.

(b) If a person wants to ingratiate himself with Harry, he *herself *she

should cook him moo-shu pork. ${ }^{23}$

That is, although semantically both men and women are included in the groups referred to by the pronouns in these sentences, only he and related masculine forms are commonly possible. An analogous situation occurs in many languages with the words for human being: in English, we find man and mankind, which of course refer to women members of the species as well. This of course permits us innumerable jokes involving 'man-eating sharks', and the widespread existence of these jokes perhaps points up the problem that these forms create for a woman who speaks a language like English.

I feel that the emphasis upon this point, to the exclusion of most other linguistic points, by writers within the women's movement, is misguided. While this lexical and grammatical neutralization is related to the fact that men have been the writers and the doers, I don't think it by itself specifies a particular and demeaning role for women, as the special uses of mistress or professional, to give a few examples, do. It is not insidious in the same way: it does not indicate to

[22] Wallace Chafe has given me an interesting example relative to this discussion of pronominal neutralization and sexism. In Iroquoian, neutralization is through the use of the feminine pronoun. The Iroquoian society is matriarchal and these two facts together would seem to be a vindication for those who claim that neutralization in favor of the masculine pronoun, as in English, is a mark of the sexism rampant in our culture. But elsewhere in Iroquoian, this claim is belied. There are numerous prefixes attached to nouns, distinguishing number, gender and case. When the noun refers to masculine human beings, these prefixes are kept separate of one another. But in referring to feminine human beings, animals, and inanimate objects, these numerous prefixes may be collapsed. This suggests that here women are considered in the category of animals and things, and lower or less important than men, contradicting the implications of the pronominal system. So this shows that even in a matriarchal society, sexism exists and has grammatical reflexes. It also suggests that pronoun-neutralization is not really the crucial issue: there are other aspects of language - in English as well as Iroquoian which are better indicators of the relationship between linguistic usage and cultural assumptions.

[23] In (25) (a), her could of course be used in an all-female group; the point is that in a mixed group, even one predominantly female, his will normally be the 'correct' form. Many speakers, feeling this is awkward and perhaps even discriminatory, attempt a neutralization with their, a usage frowned upon by most authorities as inconsistent or illogical. In (25) (b), herself and she might conceivably replace himself and he, but the effect of the sentence would be changed, not too surprisingly: the ingratiation would be understood as an attempt at (sexual) seduction, or an attempt to persuade Henry to marry the 'person'. 
little girls how they are expected to behave. Even if it did, surely other aspects of linguistic imbalance should receive equal attention. But more seriously, I think one should force oneself to be realistic: certain aspects of language are available to the native speakers' conscious analysis, and others are too common, too thoroughly mixed throughout the language, for the speaker to be aware each time he uses them. It is realistic to hope to change only those linguistic uses of which speakers themselves can be made aware, as they use them. One chooses, in speaking or writing, more or less consciously and purposefully among nouns, adjectives, and verbs; one does not choose among pronouns in the same way. My feeling is that this area of pronominal neutralization is both less in need of changing, and less open to change, than many of the other disparities that have been discussed earlier, and we should perhaps concentrate our efforts where they will be most fruitful.

But many non-linguists disagree. I have read and heard dissenting views from too many anguished women to suppose that this use of he is really a triviality. The claim is that the use of the neutral $h e$ with such frequency makes women feel shut out, not a part of what is being described, an inferior species, or a nonexistent one. Perhaps linguistic training has dulled my perception, and this really is a troublesome question. If so, I don't know what to advise, since I feel in any case that an attempt to change pronominal usage will be futile. My recommendation then would be based purely on pragmatic considerations: attempt to change only what can be changed, since this is hard enough.

I think in any case that linguists should be consulted before any more fanciful plans are made public for reforming the inequities of English. Many of these are founded on misunderstanding and create well-deserved ridicule, but this ridicule is then carried over into other areas which are not ludicrous at all, but suffer guilt by association. For instance, there have been serious suggestions lately that women have not had too much influence on the affairs of the world because the term for the thing is his-tory. They suggest that the problem could be solved by changing the word to her-story.

It should not be necessary to spend time demolishing this proposal, but it is so prevalent that it must be stopped soon. First of all, the argument at very best confuses cause and effect: it is very seldom the case that a certain form of behavior results from being given a certain name, but rather, names are given on the basis of previously-observed behavior. So anteaters are so called because they were observed to eat ants; it is not the case that the name 'anteater' was given them randomly, and they rewarded the giver of the name by eating ants, which they had not previously done. But in any event, the argument is fallacious. The word history is not derived from two English words, his + story; rather it comes from the Greek word historia, from a root meaning 'know'. The Greeks, in coining the word, did not think it had anything to do with men versus women; so it could not have been so called because men were the only ones who played a part 
in it, nor could it have been so called in order to insure that only men would have this role. In many languages, the equivalent of the English word history is related to it in appearance and origin; yet in none of them does it appear related in any way to the masculine pronoun (cf. French histoire). Yet the world's history is the same for speakers of all languages, generally speaking. This kind of thinking is both ludicrous and totally fallacious, and is discussed at undeserved length here only because the attention it has received has distracted people from thinking of more serious problems. And more recently still, I have read a suggestion that hurricanes be renamed himicanes, since the former appellation reflects poorly on women. If this sort of stuff appears in print and in the popular media as often as it does, it becomes increasingly more difficult to persuade men that women are really rational beings.

If we can accept the facts discussed in this paper as generally true, for most people, most of the time, then we can draw from them several conclusions, of interest to readers in any of various fields.

I. People working in the women's liberation movement, and other social reformers, can see that there is a discrepancy between English as used by men and by women; and that the social discrepancy in the positions of men and women in our society is reflected in linguistic disparities. The linguist, through linguistic analysis, can help to pinpoint where these disparities lie, and can suggest ways of telling when improvements have been made. But it should be recognized that social change creates language change, not the reverse; or at best, language change influences changes in attitudes slowly and indirectly, and these changes in attitudes will not be reflected in social change unless society is receptive already. Further, the linguist can suggest which linguistic disparities reflect real and serious social inequalities; which are changeable, which will resist change; and can thus help the workers in the real world to channel their energies most constructively and avoid ridicule.

2. For the teacher of second languages, it is important to realize that social context is relevant in learning to speak a second language fluently. It is also important for a teacher to be aware of the kind of language he or she is speaking: if a woman teacher unconsciously teaches 'women's language' to her male students, they may be in difficulties when they try to function in another country; if a female anthropologist learns the 'men's language' of an area, she may not be able to get anywhere with the inhabitants because she seems unfeminine, and they will not know how to react to her. Language learning thus goes beyond phonology, syntax, and semantics: but it takes a perceptive teacher to notice the pitfalls and identify them correctly for students.

3. And finally, we have something for the theoretical linguist to consider. We have throughout this paper been talking about the use of language: what can be more germane than this in formulating a theory of language? We have shown that language use changes depending on the position in society of the 


\section{LANGUAGE AND WOMAN'S PLACE}

language user, that a sentence that is 'acceptable' when uttered by a woman is 'unacceptable' when uttered by a man, or that one sentence may be 'acceptable' under one set of assumptions in the subject matter, 'unacceptable' under another. That is, it is a mistake to hope (as earlier linguistic theories have sometimes done) that the acceptability of a sentence is a yes-no or */non* decision: rather we must think in terms of hierarchies of grammaticality, in which the acceptability of a sentence is determined through the combination of many factors: not only the phonology, the syntax, and the semantics, but also the social context in which the utterance is expressed, and the assumptions about the world made by all the participants in the discourse. It is sometimes objected that this is the realm of 'pragmatics', not 'linguistics', that it reflects 'performance', not 'competence'. My feeling is that language use by any other name is still linguistics, and it is the business of the linguist to tell why and where a sentence is acceptable, and to leave the name-calling to the lexicographers. If a linguist encounters an example like The war in Vietnam is terrible, isn't it? and feels indecisive about its acceptability in various situations, it is his duty to tell exactly where his doubts lie, and why. It is as important for him to catalog the contextual situations under which a tag-question like this (or tag-questions in general) may be used, as to determine the syntactic environment in which the tag-question formation rule may apply. To stop with the latter (as is done, for example, in standard transformational grammar) is to tell half the story.

Or to take another instance: we have discussed a wide variety of problematical cases. Why can't you say, * Fohn is Mary's widower? (And this sentence is bad under any conditions, and hence is not a question of 'performance'.) Why have the meanings of master and mistress changed in a non-parallel fashion over time? Why does $H e^{\prime}$ 's a professional make different implications than She's a professional? Suppose a linguist wishes to avoid making reference to social context in his grammar. How can he deal with such cases? First, there is the problem of the nonparallelism in the use of widow and widower. He might mark the latter in his lexicon as [-NPgenitive__] or a similar ad hoc device. Or one might say that widow had underlying it a 2-place predicate, while there was a I-place predicate underlying widower. That this is ludicrous, in that it distorts the meaning of the latter sentence, is evident. In the case of professional, the theorist who excludes social context would have a slightly different problem. He has to indicate in the lexicon that there are two words professional, presumably accidental homonyms. One is restricted to women, like pregnant; the other is restricted to men, like virile. (Of course, there are obvious semantic reasons, going back to facts in the real world, in the cases of pregnant and virile, that make their gender restrictions non-ad hoc. Since this is not the case with professional, he has already introduced arbitrariness into this lexical item.) Then one sense of professional, the one restricted to women, is defined as, 'lit. or fig., a prostitute'. The other sense, specific to men, is defined, 'engaging in certain business 
activities...' or whatever. And similarly, he would in the case of master and mistress have to construct a very strange theory of historical change in order to allow these words to diverge in sense in the way in which they have.

This is not to say that these facts cannot be handled in some ad hoc fashion; my point here is merely that to take such a course is to violate the principles of valid linguistic description. First, the linguist taking this position has been forced to resort to numerous ad hoc devices purely in order to avoid generating impossible sentences while generating those that are grammatical. Secondly, and perhaps more seriously, he would be overlooking the real point of what is going on. Each of the nonparallelisms that have been discussed here (as well, of course, as the many others mentioned elsewhere in the paper, and still others the reader can no doubt supply himself) would in such treatment be non-parallel for a different reason from each of the others. Yet the speaker of English who has not been raised in a vacuum knows that all of these disparities exist in English for the same reason: each reflects in its pattern of usage the difference between the role of women in our society and that of men. If there were tomorrow, say by an act of God, a total restructuring of society as we know it so that women were in fact equal to men, we would make certain predictions about the future behavior of the language. One prediction we might make is that all these words, together, would cease to be non-parallel. If the curious behavior of each of these forms were idiosyncratic, we would not expect them to behave this way en masse. If their peculiarity had nothing to do with the way society was organized, we would not expect their behavior to change as a result of social change. Now of course, one cannot prove points by invoking a cataclysmic change that has not occurred, and, in all probability, will not. But I do think an appeal is possible to the reader's intuition: this seems a likely way for these forms to behave. In any event, I think this much is clear: that there is a generalization that can be made regarding the aberrant behavior of all these lexical items, but this generalization can only be made by reference, in the grammar of the language, to social mores. The linguist must involve himself, professionally, with sociology: first, because he is able to isolate the data that the sociologist can use in determining the weaknesses and strengths of a culture (as we have done, to some extent, here); and then because, if he does not examine the society of the speakers of the language along with the so-called purely linguistic data, he will be unable to make the relevant generalizations, will be unable to understand why the language works the ways it does. He will, in short, be unable to do linguistics. ${ }^{24}$

[24] This is not the only known situation in which the linguist must work with the concepts of sociology. To give another example, in his paper 'Anaphoric Islands' in Binnick et al. eds., Papers from the Fifth Regional Meeting of the Chicago Linguistic Society, May 1969, Postal discusses the distribution of terms like dogmeat, wombatmeat, pigmeat (as opposed to dog, chicken, pork). He suggests that -meat must appear if the item is not regularly eaten by the speakers of the language. This is another example in which reference must be made to purely cultural, extralinguistic facts about a society in order to judge the well-formedness of lexical items. 
Earlier versions of this paper have profited greatly from comments from many people. In particular I should like to thank the following people for their contributions: Wallace Chafe, Eve Clark, Herbert Clark, Richard Diebold, James Fox, David Green, George Lakoff, Susan Matisoff, Michelle Rosaldo, Elizabeth Traugott, Monica Wilson, and Philip Zimbardo. This paper was written while I was in residence at and supported by a grant from the Center for Advanced Study in the Behavioral Sciences, Stanford, California, to which I should like to express my deepest gratitude.

\section{REFERENCES}

Haas, M. R. (1964). Men's and women's speech in Koasati. In D. Hymes (ed.), Language in culture and society. New York: Harper \& Row.

Lakoff, R. (1972). Language in context. $L g .48,907-27$.

\section{EDITORIAL NOTE}

The editor hopes that Professor Lakoff's article will stimulate research and contributions to this journal. Four observations are made here in that regard.

(I) A focus on women brings to light an aspect of language in social life that has its counterpart for men. Pre-emption of the 'serious' sphere of life by a certain style of 'maleness' is not without its cost for many men. The association of male creativity in the arts with effeminacy is a well-known instance. The channelling of the range of human attributes into sterotypes for a 'lady' and a 'man' harms identity and individuality for many of both sexes, as the younger generation widely recognizes. 'Men's language' needs study too.

(2) Comparative data is needed. Work such as that of Helen Hogan on Ashanti materials (Texas Working Papers in Sociolinguistics, I, 197I) and of Elinor Keenan in Madagascar (see her paper in J. F. Sherzer and R. Baumann, The ethnography of speaking (Cambridge University Press, forthcoming - the title is tentative) can put matters in sharper focus. Women are widely denied equality in speaking, but the ways, including their compensations, are complex.

(3) The analysis of lady as a euphemism should be linked to the elaboration in English of derogatory ('dys-phemistic') terms for women. Lakoff broaches an important general topic. As we know, languages show elaboration of vocabulary in many spheres for many reasons (ecological importance, notably, in the literature but many others, including perhaps pure play). Elaboration of vocabulary with an attitudinal base may be euphemistic (the toilet example), 'dys-phemistic', or link the two, as in an ancient Chinese pair of terms, one describing the crossing of a boundary by armed force as profanation of sacred shrines, as a 